\title{
CHINA Y SU POLÍTICA DE INTERNACIONALIZACIÓN. EL CASO DE LAS ZONAS ECONÓMICAS EXCLUSIVAS (ZEE) EN ÁFRICA
}

CHINA AND ITS INTERNALIZATION POLICY. THE EXCLUSIVE ECONOMIC ZONES (EEZ) CASE IN AFRICA

GUSTAVO ALEJANDRO GIRADO

Universidad Nacional de la Matanza ARGENTINA

DANIEL KUSCHINSKI KATHMANN

Universidad de Illinois ESTADOS UNIDOS 


\title{
RESUMEN
}

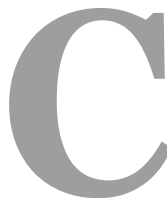

hina se ha convertido en una economía influyente a todo nivel, especialmente en lo que va del siglo XXI. Parte de su ascenso e impacto obedece a una serie de políticas vinculadas con la internacionalización de sus empresas (en el marco de una política mayor, "Go Global"), la que se desarrolla primero sobre su esfera de influencia regional, y luego en África, continente en donde sus inversiones pasan a tener gran relevancia. En su plan de relacionarse más estrechamente con economías con las cuales pretende mayores vínculos políticos y económicos, despliega su propia y exitosa experiencia de las ZEE en economías de mayor atraso relativo, con consecuencias divergentes hasta ahora.

Palabras Clave: China, ZEE, África, capacidades, desarrollo, transferencia.

\begin{abstract}
China has become an influential economy at all levels, especially so far in the 21st century. Part of its rise and impact is due to a series of policies related to the internationalization of its companies (within the framework of a larger "Go Global" policy), which is developed first in its regional sphere of influence and then in Africa, continent where their investments are called to have great relevance. In its plan to create closely relationship with economies which seeks greater political and economic ties, it deploys its own successful experience of the EEZs in economies of relative backwardness, with divergent consequences so far.
\end{abstract}

Keywords: China, EEZ, Africa, capabilities, development, transfer.

Una parte importante del enorme y acelerado progreso que transitó China durante estas últimas cuatro décadas, estuvo vinculado a una serie de políticas implementadas desde fines de la década del setenta del siglo XX, al inicio del período de profundas reformas implementadas luego del fallecimiento de Mao Zedong y ya bajo la conducción política de Deng Xiaoping. Si bien la explicación de aquel desarrollo es multicausal, sobresalen una serie de decisiones referidas a la creación de las Zonas Económicas Especiales (ZEE) y las políticas referidas a la Inversión Extranjera Directa (IED). 
Con respecto de estas últimas, China fue el destino privilegiado de la IED extranjera durante décadas, convirtiéndose en el principal receptor de entre todas las economías en vías de desarrollo, y en la medida que fue madurando y acumulando conocimiento y capitales; nos interesa particularmente el sentido de salida de la IED desde China, proceso que la convierte en exportadora de capitales desde aproximadamente 2002, para ser desde 2015 exportadora neta.

La velocidad de ese proceso no tiene antecedentes a nivel mundial, y constituye una de las claves del despegue económico chino; es el aspecto más llamativo de su proceso de crecimiento y desarrollo, estrictamente relacionado con la presencia de los capitales transnacionales dentro de su territorio. La actividad de esas empresas extranjeras radicadas en China, hoy explican aproximadamente la mitad de las exportaciones del país, y una proporción similar de las compras que se hacen desde China.

Si bien estaba prácticamente prohibida antes de 1978, con las modificaciones legales y las ZEE, la IED que ingresa a China comenzó a crecer durante la década de 1980 en la medida que las restricciones se fueron liberalizando gradualmente. Claro, el éxito en estas ZEE en términos de crecimiento económico, empleo e ingresos fiscales, facilitó reformas similares orientadas al mercado fuera de ellas.

Los movimientos de la IED china responden a una serie de factores internos y externos, entre los que destaca la política del gobierno de China, abarcativa y claramente favorable a la expansión internacional de las empresas del país, política que además de beneficios fiscales incluye el financiamiento público a los proyectos de IED.

El origen del proceso data de comienzos del corriente siglo, cuando la política del gobierno fue la de promover esos flujos de IED desde China, y cobra impulso bajo el título de "globalizarse" (zou-chu-qu, -literalmente "salir"-, política conocida en la literatura académica occidental como "Go Global”). Esta política la inició oficialmente el ex primer ministro Zhu Rongji en su informe de 2000 al Congreso Nacional del Pueblo sobre la labor del gobierno. En consecuencia, en el $10^{\circ}$ Plan Quinquenal (2001-05) las inversiones de las empresas chinas fuera de China constituían una de las claves para que la economía china se adapte por sí sola a las tendencias de la globalización.

En 2004, el primer ministro Wen Jiabao -en su discurso en la $10^{\circ}$ Asamblea Popular Nacional-, sostuvo que China debería acelerar la implementación de esa estrategia y coordinar y guiar a las inversiones chinas en el exterior más efectivamente. Se estimula así a las empresas -en todas las formas de propiedad- a invertir en operaciones en el exterior y ampliar sus cuotas de mercado internacional. Esa política "Go Global" fue ratificada y acentuada en el $11^{\circ}$ Plan Quinquenal (2006-2010).

Esta estrategia convirtió a China en una fuente emergente de capital en el mundo -mientras sigue siendo el destino favorito de capital extranjero-, pero la presencia de esa IED en el mundo sigue siendo pequeña en comparación con la de los países industrializados en términos de stock. 
Puede decirse que China constituye un nuevo actor dentro del juego de las economías más grandes (considerando que China, claro, ya forma parte de ese grupo) cuyo stock de IED es pequeño, pero ya cuenta con un flujo anual muy importante, que la coloca en la tercera posición a nivel mundial como origen de los fondos (Girado, 2013). En suma, de acuerdo a cómo se realice la medición, China es una de las dos economías más grandes del mundo, la primer potencia comercial del planeta y ahora es también una referencia importante en el terreno de las inversiones al exterior, si bien aún en términos de stock es un latecomer.

Ya en 2004 el gobierno anunció un plan para ofrecer créditos subsidiados a empresas que invirtieran en el exterior en ciertas áreas prioritarias, que significaran la adquisición de recursos naturales escasos en China, proyectos en manufactura e infraestructura que conlleven la exportación de tecnología china, y proyectos de Investigación y Desarrollo (I+D, desde aquí) y adquisiciones que fortalezcan la competitividad global de las empresas chinas.

Esa asistencia también se utiliza para apoyar la expansión internacional, cuando la financiación para la construcción de infraestructuras requiere la participación de empresas chinas. Desde aquel momento y durante los siguientes seis años, el país termina concretando 127 tratados bilaterales de inversión y 112 acuerdos de doble tributación, lo que es una política congruente con su creciente inversión directa en el exterior.

Dicho esto, la situación actual resulta en que la cantidad de acciones en manos de capitales chinos (las salidas de IED desde China) constituyen un stock relativamente pequeño pero creciente, y que es de sólo una cuarta parte del monto acumulado de IED que está en manos de extranjeros dentro de China.

Sin embargo, el surgimiento de China como una fuente de IED en el mundo puede ser considerado como un paso lógico en el desarrollo económico del país; todo indica que China continuará buscando oportunidades de inversión en el extranjero en el futuro, siendo probable que las salidas de IED desde China se aceleren.

Los flujos de IED han crecido sistemáticamente desde 2002, y más que se duplicaron entre 2007 y 2008, cuando los inversores chinos se encontraron en una situación financiera casi privilegiada, vis a vis la posición financiera de gran cantidad de corporaciones que estaban padeciendo las consecuencias de la crisis internacional que, en ese momento, estaba comenzando a manifestarse. Pudieron aprovecharse de la crisis que estaba afectando seriamente a los países más desarrollados.

A fin de 2012 más de 16 mil entidades chinas habían establecido fuera de China unas 22 mil empresas en 179 países, otorgando a China el $30^{\circ}$ lugar en el mundo por inversiones acumuladas, con us \$531,9 mil millones. En suma, aunque las empresas chinas son "latecomers" en términos de inversores fuera de su lugar de origen, ya se han aventurado a una enorme cantidad de países y en muy variados sectores.

Por región, Asia fue el principal destino de la IED de China explicando el 71,4\% del total de ese stock de IED a fin de 2011, y luego aparece Latinoamérica con el 13\% del stock. Sin em- 
bargo, el 92\% de esa cifra ha sido destinada a las Islas Vírgenes y las Islas Caimán, que son dos paraísos fiscales bajo control británico. El 8\% restante fue dirigido principalmente a Brasil, Perú, Venezuela y Argentina. El tercer destino fue Europa, seguido por África, América del Norte y Oceanía, en ese orden (OECD, 2015).

En 2013, grupos chinos invirtieron en 5.090 empresas en el extranjero, en 156 países y regiones, por más de us $\$ 100$ mil millones, con las inversiones no-financieras creciendo un $26 \%$, lo que permite afirmar que el gobierno de China ha consolidado ampliamente su estrategia "Go Global".

En ese proceso es cuando África y Latinoamérica afloran por sobre la media como destino privilegiado de los capitales chinos extraregionales, mientras las economías del hemisferio norte occidental reciben capitales chinos pero como compradores de tecnología y marcas, ya que no solo pretenden abastecerse o conseguir insumos para llevar a su territorio, sino también desarrollar mercados en Europa y América del Norte y comprar, en ellos, tecnología occidental y marcas consolidadas para poder gestionarlas dentro de su territorio y competir dentro de él.

Consultoras internacionales advierten que no necesariamente los chinos desean conquistar mercados externos, sino que uno de sus principales desafíos es desarrollar y asegurarse el propio, que es considerado como potencialmente el más grande del mundo.

Durante la década posterior (2004-2014), entonces, la adquisición de empresas no chinas por parte de capitales chinos se acelera notablemente. Esas inversiones van paulatinamente consiguiendo sus objetivos porque para ambos propósitos cuentan con formatos relativamente desconocidos en occidente, y que para avanzar en mercados externos les resultan especialmente convenientes: ese proceso de internacionalización es encabezado por empresas estatales chinas, que van a otros países con una propuesta cerrada como inversiones corporativas, de una sola entidad, crédito barato y otros beneficios.

\section{ZONAS ECONÓMICAS ESPECIALES CHINAS. EL CASO DE ÁFRICA}

Las ZEE fueron originalmente espacios para atraer a los inversores extranjeros, donde se les brindaba un trato preferencial, pero también -y especialmente- fueron los lugares elegidos para hacer los ensayos de las reformas, que entonces eran incipientes.

En 1980 se establecieron en China cuatro ZEE: tres de ellas localizadas en la provincia costera de Guangdong (en las ciudades de Shenzhen, Zhuhai y Shantou) y la cuarta en la provincia costera de Fujian (en la ciudad de Xiamen). Estas ZEE ofrecían incentivos a los inversores extranjeros, incluyendo bajas tasas impositivas, privilegios en el intercambio de divisas, bajos costos para el uso de la tierra y una mayor autonomía económica.

Para reforzar las ventajas de las zonas costeras, se implementan políticas de inversión diferentes a las vigentes en el resto del país, y con tratamiento impositivo preferencial, junto con reglas 
de empleo más flexibles, burocracia más eficiente e inversiones en infraestructura. Esas ZEE, junto a otros instrumentos de atracción de IED, impulsaron la economía de las provincias costeras.

Entre 1980 y 1985 esas ZEE se dedicaron fundamentalmente a la construcción de obras de infraestructura en gran escala, y a crear lo que suele denominarse "medioambiente atractivo" para las inversiones; en una etapa posterior -entre 1986 y 1995-, se consagraron a desarrollar la economía exportadora centrada en la industria procesadora para exportar desde allí.

Ampliando la experiencia, en 1984 catorce ciudades portuarias (del este) fueron señaladas como "ciudades litorales abiertas al exterior", en las cuales la inversión extranjera gozaría de un trato preferencial, pero a un escalón por debajo de las ZEE con respecto de los beneficios y prerrogativas ${ }^{1}$. El crecimiento chino, su demanda creciente de insumo agroalimenticios y energéticos, y su ascenso global como inversor, pone al continente africano en el radar chino casi automáticamente.

Estas economías africanas han seguido modelos de desarrollo europeo por muchas décadas sin lograr los beneficios previstos ni poder sacar a sus habitantes de la pobreza (Madakufamba, 2016); por lo tanto, cuando el Ministerio de Comercio Chino (MOFCOM) anunció en 2006 su intención de establecer cincuenta ZEE en el extranjero como parte de su política de "Go Global”, los gobiernos africanos se aseguraron de que sus países fueran los anfitriones más importantes, tomando siete de las primeras diecinueve ZEE planeadas (Dannberg, Yejoo y Schiller, 2013)². Recientemente, otras zonas de inversión china se establecieron en Uganda, Nigeria, Mozambique y Etiopía (Tang, 2015).

Entre otros motivos, el encarecimiento de la mano de obra china en la medida que el país se industrializa es uno de los principales, y de allí que requieran reestructurar su sistema productivo transfiriendo sus industrias mano de obra intensivas, maduras y menos productivas, hacia África, para aprovechar la mano de obra barata en el continente. Al mantener sus industrias productivas y de alta tecnología, las compañías chinas pueden producir bienes cada vez más sofisticados y ascender en la cadena de valor.

La producción en África es útil para las firmas chinas debido a que este continente sirve como plataforma para eludir barreras proteccionistas contra el país y permite la exportación desde allí de sus productos hacia Europa y América. Egipto, por ejemplo, incentivó la inversión en su ZEE declarando que todo producto generado dentro de ésta obtendría el certificado de origen del país.

Las ZEE también incrementan las exportaciones de maquinaria china necesaria para la producción en los países africanos. A éstos (particularmente Nigeria y Egipto, puesto que tienen grandes mercados domésticos) se les puede vender sin barreras arancelarias ${ }^{3}$ ni costos de envío (Brautigam y Xiaoyang, 2011).

\footnotetext{
${ }^{1}$ La apertura continuó y fueron creadas las Zonas de Desarrollo Económico Costero (ZDEC): en el Delta del Rio Yangtsé, el Delta del Rio Perla, y el triángulo de Xiamen - Zhangzhou - Quanzhou (en 1985). En 1990 el gobierno central autorizó al municipio de Shanghai a abrir al exterior la zona de Pudong, haciendo del proceso un verdadero emblema tal que, veinte años después, la imagen del barrio sea la síntesis de la dinámica de China al convertirse, también, en uno de los centros financieros más importantes del mundo. Esa imagen ya es icónica y hace las veces de verdadero emblema del progreso económico chino.

${ }^{2}$ En Argelia, Egipto, Etiopía, Mauricio, Nigeria (dos) y Zambia.

${ }^{3}$ En Chen se explica que Nigeria aplica un arancel de $70 \%$ a autos importados, creando incentivos para el ensamblado doméstico.
} 
En general, los países africanos se encuentran subdesarrollados, con infraestructura de baja calidad, un nivel educativo muy pobre y un alto índice de desempleo. El incremento de la demanda de materias primas africanas por parte de los nuevos países emergentes ${ }^{4}$ aumentó las reservas de varios de estos países. Las ZEE formadas en el continente pueden contribuir a que estas reservas se transformen en desarrollo e industrialización, al reforzar la sofisticación de su sistema industrial, proporcionándoles infraestructura, una administración de clase mundial, empleos mejor pagados, conocimientos tecnológicos y maquinaria de alta tecnología $^{5}$ (Farole, Brautingam y Xiaoyang, 2010), si es que se consigue realizar la transferencia de tecnología inherente.

Gracias a los requerimientos impuestos por los gobiernos africanos ${ }^{6}$, las ZEE chinas en África han empleado en su mayoría a obreros locales, disminuyendo así el desempleo y permitiendo la transferencia de conocimientos. En 2009, la ZEE en Zambia tenía 700 trabajadores chinos y 3.300 zambianos (Brautigam et al., 2011). En Nigeria, los trabajadores chinos solo constituyen 20\% de la fuerza laboral (Chen, 2016).

Para facilitar aquel derrame tecnológico es necesario crear un enlace entre las firmas locales que se encuentran fuera de las ZEE, y las empresas chinas dentro de éstas. Este enlace precisa la creación, por parte del gobierno local, de infraestructura fuera de las ZEE, como caminos de acceso a fuentes de energía, agua, gestión de residuos, tecnologías de información y comunicación e instalaciones portuarias (The World Bank, 2011).

Con estos enlaces, los proveedores de insumos locales podrían entrar en las cadenas globales de valor, hacerse de un potencial mercado internacional más amplio y obtener conocimientos y tecnologías de las grandes empresas chinas. Para favorecer el traspaso de conocimientos -y dada la experiencia china al respecto- se requiere la creación de vínculos entre las firmas chinas y los institutos de I+D y universidades locales. Además, se requiere de la generación de facilidades para la inversión local dentro de la ZEE, con lo cual las firmas domésticas puedan aprender mediante la cercanía de firmas extranjeras.

Debido a que los empresarios africanos no poseían las habilidades y conocimientos necesarios, varias de las ZEE que intentaron emplear administración local desde el comienzo tuvieron dificultades para aplicar sus proyectos. Debido a ello y para que los administradores africanos no obstaculizaran el avance temprano de los mismos, resultó más eficiente comenzar con una gerencia china y gradualmente planear y educar a los empresarios africanos para que la administración pasara -paulatinamente- a sus manos7. En Egipto se implementó un sistema inicialmente exitoso en el que existían varios socios locales en la creación de la ZEE sin que éstos se encontraran al comienzo en posiciones gerenciales (Brautigam et al., 2011).

\footnotetext{
${ }^{4}$ Sobre todo de algunos BRIC (Rusia, India y China).

${ }^{5}$ En el trabajo de Brautigam et al. y tal como lo hizo Japón en los años setenta con varios países del sudeste asiático, se explica cómo se produjo el desplazamiento de economías agrícolas a economías con un sistema industrial más productivo en pocos años.

${ }^{6}$ Egipto, por ejemplo, daba sólo una visa de trabajo por cada 9 egipcios empleados.

${ }^{7}$ En estas ZEE en África, a las compañías chinas se les han otorgado concesiones de 50 a 99 años, después de lo cual pasarán a manos locales africanas.
} 
Aunque la política de "Going Global" mencionada otorga subvenciones, préstamos a largo plazo, subsidios y ayuda diplomática a compañías chinas para la creación de las ZEE en el exterior, las firmas encargadas de llevarlo a cabo en África fueron mayoritariamente del sector privado chino. Farole et al. (2010) argumentan que para el lanzamiento exitoso de las ZEE fue fundamental el incentivo de lucro. De acuerdo a algunos analistas, la experiencia internacional mostraría que las ZEE privadas han operado de manera más efectiva y son más sustentables que las dirigidas por el gobierno. Además, varias de estas firmas tenían mucha experiencia, porque fueron las mismas que formaron las ZEE con éxito en China.

Zhang y Ilhéu (2014) explican que "los países menos desarrollados ven con admiración la modernización económica y el desarrollo chino y se preguntan qué experiencias y lecciones pueden aprender de su éxito". Al encontrarse en una situación similar a la que estaba China al formar sus ZEE, si los países africanos logran simular el proceso, entienden que hay chances de éxito.

Las ZEE de China triunfaron por varias razones. El gobierno implementó una política de "puertas abiertas", el cual incentivaba la entrada de IED con políticas preferenciales. Se construyó la infraestructura necesaria y se escogieron zonas cercanas a la costa con salida fácil al resto del mundo. Se otorgaron incentivos para atraer diásporas chinas educadas en países más desarrollados y se invirtió en industrias tecnológicamente avanzadas. Se mantuvo la flexibilidad y la capacidad del gobierno para cambiar las regulaciones y políticas dentro de las ZEE y se actuó de manera gradual, usando las ZEE como un laboratorio en el cual se probaron distintas reformas para tomar en cuenta el aprendizaje antes de aplicarlas de manera nacional (Zhang et al., 2014).

En Zhang et al. (2014) analizaron el caso de la ZEE "Manga-Mungassa” en Mozambique y llegaron a la conclusión que tenía altas probabilidades de éxito gracias a que seguía estrechamente el sistema de desarrollo de las ZEE en China ${ }^{8}$. El gobierno de Mozambique estaba determinado a usar las ZEE chinas como modelo para el desarrollo e implementó políticas para atraer inversión a su ZEE, actuando de manera gradual en su creación. Su ubicación es estratégica pues tiene acceso al mar y es la entrada a varios países vecinos. Mozambique tiene diásporas en el extranjero que pueden invertir en la ZEE y, como China, ha logrado una transición gradual hacia una economía de mercado.

Sin embargo, hay factores que son menos favorables en ciertos países, sobre todo los concernientes a la participación y determinación hacia las ZEE por parte de los gobiernos africanos. Algunos gobiernos han creado infraestructura insuficiente, otros han tenido menos interés en aprender sobre las ZEE y han brindado poca información a su habitantes sobre ellas (Farole et al., 2010) ${ }^{9}$ y otros más no han realizado políticas que faciliten la inversión. La construcciónón de la ZEE en Argelia fue suspendida por "cambios inesperados en la legislación argelina que rige a la inversión extranjera” (Brautigam et al., 2011).

\footnotetext{
${ }^{8}$ El análisis fue hecho en 2014 cuando la ZEE estaba en su etapa inicial de desarrollo; habrá que observar su desarrollo posterior para evaluarla correctamente.

${ }^{9}$ Por falta de transparencia han surgido sospechas de corrupción o mal manejo resultando en protestas de comunidades locales como en la zona Lekki en Nigeria.
} 
Varios autores como Ancharaz (2013) y Dannberg et al. (2013), expresan razones por las cuales las ZEE posiblemente no funcionarían. En primer lugar indican que el número de ZEE en África es demasiado pequeño para hacer una diferencia en el continente y temen que China solo busque ejercer un "poder suave" en la región a cambio de trabajos de bajo nivel y promesas de derrame tecnológico no fundamentadas. Les inquieta que las ZEE se vuelvan enclaves chinos aislados, pues los enlaces con las economías locales son inadecuados y muchas manufactureras chinas importan insumos de su país. Expresan su preocupación acerca de que las importaciones de productos baratos y el establecimiento de grandes firmas chinas en las ZEE pudiesen herir la economía local y causar el desplazamiento de las firmas locales.

En contraste, Tang (2015) explica que inversionistas extranjeros en varias ZEE se han reunido con proveedores fuera de las zonas e invitado a compañías locales a invertir dentro de las ZEE para crear una cadena de valor y red de proveedores completa. El gobierno chino entrenó a decenas de miles de oficiales locales al invitarlos a visitar las ZEE, tomar cursos sobre ellas y participar dentro por un tiempo.

Las ZEE se han vuelto plataformas para que chinos y africanos compartan experiencias, discutan políticas y trabajen juntos para lograr cambios prácticos e importantes. Ancharaz (2013) comenta que compañías chinas invierten menos en África para buscar recursos naturales, como lo hacían en los años noventa, y más para acceder a mercados, lo cual industrializa el continente. Chen (2016) encontró varios casos de transferencia tecnológica positiva en las ZEE en Nigeria y, por medio de entrevistas, encontró que los empresarios nigerianos respondían positivamente respecto a las relaciones económicas y técnicas con sus socios chinos.

Las ZEE chinas en África han tenido un comienzo difícil y lento debido a desafíos políticos, financieros y culturales inesperados. Sin embargo, para 2015, cinco de las siete ${ }^{10} \mathrm{ZEE}$ inicialmente planeadas ya estaban en funcionamiento. Las zonas más avanzadas en Egipto y Zambia ya tenían de veinte a treinta fábricas operando. La ZEE en Zambia desarrolló plantas grandes de procesamiento mineral y la de Egipto tiene una notable producción de maquinaria. La ZEE en Etiopía posee la fábrica de zapatos más grande del país y las dos ZEE nigerianas producen materiales para construcción y bienes para el consumo. Las cinco zonas combinadas han creado alrededor de veinte mil trabajos para africanos (Tang, 2015).

Aún es demasiado pronto para evaluar los impactos reales de las ZEE. Tang (2015) explica que en China las ZEE necesitaron de doce a quince años para madurar y en África probablemente necesiten más tiempo debido a las diferencias culturales, la ineficiencia administrativa y la falta de infraestructura por fuera de las ZEE.

Según un administrador de una ZEE en 2015, varias de éstas posiblemente despeguen y comenzarán a lograr un crecimiento significativo en un plazo que va de los cinco a diez años. Las ZEE podrán prosperar si son flexibles y sus diseños se personalizan y adaptan a las características y los requerimientos africanos, lo cual necesitará mucho trabajo por parte de los go-

${ }^{10}$ Sólo la ZEE en Mauricio no ha empezado operaciones y la de Argelia fue suspendida. 
biernos y el sector privado de cada país. Varias de estas zonas, sin embargo, ya se encuentran en operación y otras más están en construcción, dando esperanzas de que logren su objetivo: la transferencia de las industrias maduras chinas de mano de obra intensiva hacia África y un primer paso hacia la industrialización y el desarrollo económico de los países africanos.

\section{REFERENCIAS BILBIOGRÁFICAS}

Ancharaz, V. (2013). "Can Chinese SEZs spur industrial development in Africa?", International Centre for Trade and Sustainable Development http://www.ictsd.org/bridgesnews/bridges-africa/news/can-chinese-sezs-spur-industrial-development-in-africa

Bräutigam, D., \& Xiaoyang, T. (2011). “African Shenzhen: China's special economic zones in Africa”, The Journal of Modern African Studies, 49(01), 27-54.

Chen, Y. (2016). "Learning from China?: Manufacturing, investment, and technology transfer in Nigeria”.

Dannenberg, P., Yejoo, K., \& Schiller, D. (2013). "Chinese Special Economic Zones in Africa: a new species of globalisation? African East-Asian Affairs, (2).

Farole, T., Brautigam, D., \& Xiaoyang, T. (2010). "China's investment in African special economic zones: Prospects, challenges, and opportunities”, World Bank-Economic Premise, (5), 1-6.

Girado, Gustavo Alejandro (2013). "La metamorfosis exportadora china y sus implicancias globales (1980 - 2010)", en “CICLOS en la historia, la economía y la sociedad”, Año XXI, Vol. XX, No 41 Año 2012-2013, Fundación de Investigaciones Históricas, Económicas y Sociales (FIHES) de la Facultad de Ciencias Económicas de la Universidad de Buenos Aires (UBA).

Madakufamba,M.(2016). “Africa:TheRoleofSpecialEconomicZonesin China's Development Prospects for Africa”, All Africa Global Media. http://allafrica.com/stories/201512020430.html

Tang, X. (2015). "How do Chinese 'special economic zones' support economic transformation in Africa”, Supporting Economic Transformation.

OECD (2015). "Economic Surveys. CHINA", online http://www.oecd.org/eco/surveys/ China-2015-overview.pdf, March 2015. 
The World Bank (2011). "Chinese Investments in Special Economic Zones in Africa: Progress, Challenges and Lessons Learned”. The World Bank: 1-93.

Zhang, H., \& Ilhéu, F. (2014). “The Role of Special Economic Zones in African Countries: Development and the Chinese FDI”, Working Paper, 129, Lisbon: School of Economics and Management, online: https://pascal.iseg.utl.pt/ cesa/files/Doc_trabalho/WP129.pdf

\section{CURRICULUM VITAE}

\section{Gustavo Alejandro Girado}

Magister en Relaciones Internacionales (FLACSO) y Licenciado en Economía (UBA). Profesorinvestigador en la Universidad Nacional de La Matanza (UNLaM); docente regular en la Universidad de Buenos Aires (UBA); Co-coordinador de la "Diplomatura en Gestión de Negocios con China" en la Universidad Nacional de Córdoba (UNC), y docente invitado de posgrado en universidades nacionales. Dirigió y dirige proyectos de investigación en universidades nacionales (UBA CyT en UBA, PROINCE en UNLaM) sobre los temas de su competencia: comercio, inversiones, integración y relaciones internacionales; es director de Asia \& Argentina. Fue consultor en los Ministerios de Economía, de RR.EE. y de Agricultura de la Nación, en el Proyecto Okita II (acuerdo argentino - japonés) y Coordinador de Proyecto BID sobre Asia Pacífico, China y Argentina, en el Ministerio de Economía; también fue Gerente de Investigaciones en la Comisión Nacional de Comercio Exterior (CNCE). Con estudios de especialización realizados en Japón, Taiwán, R. P. China y la Cepal (en Bolivia), es autor del libro "Comercio Argentina - Asia Pacífico: una carrera de obstáculos”, de capítulos de libros y de numerosos artículos en medios gráficos. Expositor y panelista en congresos (en Argentina y el extranjero), cursos y seminarios sobre la economía de Asia en general y de China en particular, es par evaluador de la CONEAU, regularmente dirige aspirantes de maestría y es jurado de tesis, y obtuvo diversas distinciones nacionales (UBA, Fundación de las Américas) y una regional (ONU/Cepal).

ggirado@yahoo.com

\section{Daniel Kuschinski Kathmann}

Magister en Relaciones Económicas Internacionales (UBA, 2016; director Gustavo Girado) y Licenciado en Negocios Internacionales (Universidad de Illinois, 2011). Director de ventas internacionales a Latinoamérica LTC Corporation. Previamente fue director de ventas internacionales para Blue Bear Booster y Orion technology, ambas en Taiwán. Hizo una pasantía en PWISS en ventas internacionales de servicios de compra al mercado latinoamericano (Taiwán). Como parte de sus tareas profesionales participó en shows de autopartes como 
SEMA (Las Vegas, EUA), Expotransporte (Guadalajara, México), Automechanika (Ciudad de México, México), NFPA Expo (Las Vegas, EUA) y FIREX International (Londrés, Inglaterra). daniel.kuschinski@gmail.com 